\title{
Definición de un marco teórico para comprender el concepto del desarrollo sustentable
}

Definition of a theoretical framework for understanding the concept of sustainable development

Luz Alicia Cárdenas Jirón

\section{Filiación}

Académica del Departamento de Urbanismo de la F.A.U. Universidad de Chile

\section{Resumen}

Se contribuye a la comprensión de un concepto recurrente en el campo profesional, académico y político, como es el Desarrollo Sustentable. Se pretende aclarar el significado del Desarrollo Sustentable, situarlo en un contexto, entender el proceso gestacional e ilustrar con un ejemplo latinoamericano. En primer lugar, se hace referencia a un contexto global político económico existente en la segunda mitad del presente siglo. Luego se elabora un marco teórico de referencia para conocer el significado y los diferentes enfoques asociados al Desarrollo Sustentable. A partir de ello, se plantean agendas para concretar y avanzar hacia esta modalidad de desarrollo, las cuales enfatizan el nivel local como sólido punto de partida. Se muestra un caso de planificación y gestión sustentable mundialmente reconocido, la ciudad de Curitiba.

\section{Palabras clave}

Desarrollo sustentable.

\begin{abstract}
It contributes to the understanding of the concept of sustainable development. First, referring to a global political context existing economic in the second half of this century. Then develops a theoretical framework for the meaning and the different approaches related to sustainable development. From this, it raises agendas to realize and move towards this type of development, which emphasize the local level as a solid starting point. Shows the case of the city of Curitiba, with proper planning and sustainable management recognized.
\end{abstract}

\section{Key words}

Sustainable development.

\section{Sumario}

Introducción

1.- El contexto mundial en la segunda mitad del siglo XX

2.- El marco teórico del Desarrollo Sustentable

3. -Las nuevas agendas políticas para los 1990 y la Agenda Local 21.

4.- Un paradigma de Gestión Urbana Sustentable

5.- Conclusiones

Referencias 


\section{Introducción}

Este escrito pretende entregar un marco teórico para la comprensión del concepto de Desarrollo Sustentable, que despierta un creciente interés en los ámbitos del desarrollo de los asentamientos humanos. El objetivo es elaborar una base para introducir al lector no especialista en la materia y que debe trabajar ineludiblemente en este marco, ya sea en el ámbito académico, técnico profesional, administrativo, gubernamental u otro y espera constituirse en un material de apoyo para todos los que deben tomar decisiones en su campo de competencia.

Es así como en primera instancia se presenta el contexto político mundial en la segunda mitad del siglo XX, a fin de comprender como y porque surge el concepto que es insertado en el nuevo modelo de desarrollo de los piases desarrollados y en vías de desarrollo. Luego se elabora un marco teórico que proponga algunas definiciones y familiarice al lector con la terminología empleada, junto con indicar los enfoques y tendencias que se están manifestando en las disciplinas, instituciones gubernamentales y los sectores de la economía. Como paso siguiente se indican las actuales agendas políticas globales y locales que están influenciando y perfilando las políticas de los gobiernos, las reestructuraciones institucionales, los instrumentos de control, la legislación, la planificación y gestión, los planes, proyectos, propuestas de acción, etc.

Después se sitúa el concepto y sus alcances en una dimensión urbanística, conocida como "Ciudad Sustentable" en respuesta a las marcadas tendencias mundiales hacia la urbanización de los asentamientos urbanos y reconocimiento de la ciudad como entidad clave para alcanzar una productividad económica, emprender acciones de tipo ambiental y la cercanía con los sectores poblacionales más pobres. (Girardet, 1992). En la escala local se piensa que esta la base de este proceso, como lo afirma el eslogan internacional, "... actuar localmente, pensar globalmente..."

Finalmente, se muestran algunos casos paradigmáticos actuales de Gestión Urbana Sustentable.

En ciudades latinoamericanas y europeas ejercidas desde el ámbito municipal de gobierno y se plantean algunas reflexiones finales a modo de conclusión.

\section{1.- El contexto mundial en la segunda mitad del siglo $X X$}

Para comprender el surgimiento del concepto Desarrollo Sustentable, es necesario conocer previamente el contexto en el cual se va gestando y finalmente surge esta nueva orientación conducente al desarrollo de los países para el próximo milenio. Para ello, se estima conveniente revisar retrospectivamente la situación política, económica, social y ambiental durante los últimos 50 años en el mundo. 
La tabla No 1 muestra una sinopsis de los principios rectores que regían la conducción de los gobiernos en materias de índole político, económico, social, ambiental, financiamiento y gestión, tanto en países desarrollados como en vías de desarrollo.

Como puede verse en la tabla, los principios y líneas conductoras del desarrollo en la última mitad de siglo XX han ido evolucionado acorde a las experiencias previas de la aplicación de los modelos en los países; las lecciones aprendidas de la praxis; las nuevas corrientes de pensamiento en las disciplinas y los intereses de los organismos mundiales de financiamiento y agencias de cooperación al desarrollo de los asentamientos humanos, tales como World Bank, PNUD, Habitat, OECD, WHO, etc.

A fin de exponer brevemente las orientaciones políticas gubernamentales se ha dividido la segunda mitad de siglo en cuatro periodos claramente identificados según la política económica imperante y los modelos de desarrollo subyacentes. El periodo 1940 - 1960; la década 1970; la década 1980; y la década actual de 1990.

En breve, en el periodo 1940 / 1960, posterior a la recesión mundial de los anos treinta, se elabora una política de la "modernización" la cual modifica el modelo económico existente basado en las importaciones de bienes por un nuevo modelo de substitución a las importaciones con lo cual se inicia un proceso acelerado de industrialización, siendo notable el caso de Latinoamérica que se institucionaliza para promover estos objetivos con la creación de la CEPAL (Comisión Económica para América Latina) o ECLA (Economic Comission for Latin America), en Santiago de Chile. (Harris, 1992). En contraste al crecimiento económico nacional experimentado por los países, se observa en el periodo un aumento significativo de la población urbana, producto de las migraciones campo/ciudad en busca de oportunidades laborales, que va dejando como saldo migratorio a cientos de personas sumergidas en absoluta pobreza.

El pensamiento de la política económica de la época sostenía que el fenómeno del "chorreo", vale decir, el excedente de la producción económica, beneficiaria a toda la sociedad, ya que el mercado actuaría como el regulador de la distribución de riquezas e ingresos para la población y con ello también los sectores pobres.

En el período de los 70, surge un nuevo modelo de desarrollo en respuesta a los efectos sociales derivados de la "modernización" y es conocido como la política de las "Necesidades Básicas", que pretende en primera prioridad satisfacer las necesidades básicas de los asentamientos humanos, particularmente los más pobres. Esto significa, entre otros, la creación de empleos, la ejecución de infraestructuras, la construcción de viviendas y el equipamiento básico mediante un enfoque estrictamente sectorial de los proyectos de inversión pública. En este sentido el rol del Estado es asumido como un proveedor de servicios sociales.

El pensamiento de la política económica en esta década es la distribución del crecimiento económico con equidad para lo cual el sector público adquiere un gran peso como actor principal conductor del desarrollo. Una de las críticas que se han hecho a esta política es el estancamiento del crecimiento económico, el gran déficit en la balanza de pagos por un aumento irrestricto del gasto social y un incremento de la deuda externa.

A final de los setenta se produce una crisis económica global derivada, entre otros, del alza sustantiva en el precio del petróleo en 1979, lo cual lleva a una recesión mundial que modifica la política económica de los países desarrollados, orientándose esta vez hacia la desregulación del mercado. Esta situación trae como consecuencia la eliminación de barreras económicas para el libre mercado, una reducción de la demanda por productos primarios proveniente de los países 
Definición de un marco teórico para comprender el concepto del desarrollo sustentable Definition of a theoretical framework for understanding the concept of sustainable development

en desarrollo, una baja en los precios de estos productos y la disminución de divisas para mantener su economía funcionando, lo cual genera un gran déficit en la balanza de pagos. Así, los países en desarrollo se ven forzados a solicitar préstamos a organismos como el Banco Mundial y el Fondo Monetario Internacional, quienes a cambio le imponen modelos de desarrollo económico fundados en el neoliberalismo. (Hunt, 1989)

Es así como en los ochenta, se implanta el modelo neoliberal conocido como la política del "Ajuste Estructural." En el plano social, se invierte en recursos humanos a largo plazo vía la capacitación, se reduce significativamente el gasto social en sectores claves para el desarrollo y bienestar social como educación, salud, previsión, vivienda, etc. y se entrega la otorgación de estos servicios al sector privado por considerarlo más eficiente que el sector público en la asignación de los recursos, aunque no necesariamente más equitativo. Se cree que una forma de combatir la pobreza es mejorando la productividad pues así se van a generar nuevos y más empleos junto con riquezas que alcanzaran a todos los sectores sociales. No obstante, una de las críticas más evidentes del periodo fue el aumento de la brecha entre los sectores acomodados y los más pobres, pues en la realidad los sectores desposeídos llegaron a ser más pobres aun y viceversa.

El pensamiento de la política económica en los ochenta postula la liberalización económica en donde el mercado actúa como regulador y con ello se definen acciones e instrumentos políticos tal como la virtual suspensión de las restricciones económicas a las importaciones, la explotación indiscriminada de los recursos naturales como fuente básica para la producción económica y exportaciones, el uso ilimitado de las infraestructuras urbanas existentes, la competencia de los servicios públicos vía un proceso de privatización, etc. Los actores principales del desarrollo son el sector privado y el sector público como subsidiario del anterior.

A fines de los setenta y durante la década de los ochenta comienza ya a debatirse mundialmente las problemáticas ambientales que afectan tanto al globo terráqueo como a los países localmente y adquiere tal relevancia este tópico que en los noventa alcanza los escenarios políticos llegando a ser un componente más a considerar en los modelos de desarrollo. Aunque en primera instancia aparece como una dicotomía conceptual entre el desarrollo y el medioambiente, luego se demuestra que el desarrollo económico y la gestión ambiental son aspectos complementarios de una misma agenda. (World Bank, 1992)

Es así como en los noventa se plantea el modelo del "Desarrollo Sustentable" como la opción para abordar simultáneamente los desafíos que enfrentan los asentamientos humanos a fines del siglo XX, a saber: los flagelos de la pobreza, la destrucción sostenida del medioambiente y el crecimiento económico.

En el plano social, figura con gran relevancia el tópico del "genero" que pretende establecer un reconocimiento político de las diferencias y requerimientos existentes para el desarrollo de hombres y mujeres en la sociedad. En concreto, una de las reivindicaciones principales es la discriminación hacia la mujer en el ámbito laboral y la planeación urbana.

En el plano económico surge como un imperativo la necesidad de elevar la productividad económica ya no entendida solamente como sinónimo de crecimiento económico sino también la internalización de una evaluación de la relación insumo / producto existente por cada unidad de producción resultante; asignando esta vez una valoración al uso de recursos humanos y ambientales. 
RERERADENSO

http://revistaurbanismo.uchile.cl
Definición de un marco teórico para comprender el concepto del desarrollo sustentable

Definition of a theoretical framework for understanding the concept

Tabla $\mathbf{N}^{\circ} 1$. -Sinopsis del contexto político internacional en la segunda mitad del siglo $\mathbf{X X}$

\begin{tabular}{|c|c|c|c|c|}
\hline Aspectos & 1940 / 1960 & 1970 & 1980 / 1990 & 1990 / \\
\hline Político & Modernización & $\begin{array}{l}\text { Necesidades } \\
\text { Básicas }\end{array}$ & Ajuste Estructural & $\begin{array}{l}\text { Desarrollo } \\
\text { Sustentable }\end{array}$ \\
\hline Económico & $\begin{array}{l}\text { Modelo de } \\
\text { crecimiento } \\
\text { económico: } \\
\text { Substitución de las } \\
\text { importaciones. }\end{array}$ & $\begin{array}{l}\text { Modelo de } \\
\text { distribución del } \\
\text { crecimiento } \\
\text { económico con } \\
\text { equidad. } \\
\text { Solicitud de créditos }\end{array}$ & $\begin{array}{l}\text {-Reforma económica. } \\
\text { Promoción de } \\
\text { liberalización de } \\
\text { economía, } \\
\text { (neoliberalismo) } \\
\text { privatización, pago de } \\
\text { Deuda Externa }\end{array}$ & $\begin{array}{l}\text { Enfoque trial: } \\
\text { crecimiento } \\
\text { económico, } \\
\text { aliviación de } \\
\text { pobreza, y } \\
\text { protección } \\
\text { ambiental. }\end{array}$ \\
\hline Social & $\begin{array}{l}\text { "Trickle down", o } \\
\text { fenómeno del } \\
\text { "chorreo", beneficiaria } \\
\text { a toda la sociedad, } \\
\text { pues el mercado } \\
\text { actuaría como } \\
\text { regulador de } \\
\text { recursos. }\end{array}$ & $\begin{array}{l}\text {-Satisfacción de } \\
\text { necesidades básicas } \\
\text { vía proyectos } \\
\text { sectoriales (salud, } \\
\text { educación, } \\
\text { infraestructura, } \\
\text { vivienda, nutrición, } \\
\text { etc.). } \\
\text {-Participación } \\
\text { popular. } \\
\text {-Necesidad de crear } \\
\text { empleo para aliviar } \\
\text { la pobreza }\end{array}$ & $\begin{array}{l}\text {-Inversiones en } \\
\text { recursos humanos a } \\
\text { largo plazo. } \\
\text { (Capacitación,...) } \\
\text {-Combate de la } \\
\text { pobreza vía aumento } \\
\text { productividad. } \\
\text {-Reducción gasto } \\
\text { social (salud, } \\
\text { educación, pensiones, } \\
\text { etc.) } \\
\text {-En pro de eficiencia } \\
\text { económica, se } \\
\text { entregan servicios } \\
\text { básicos vía } \\
\text { privatización. }\end{array}$ & $\begin{array}{l}\text {-Surge } \\
\text { fuertemente la } \\
\text { corriente del } \\
\text { "genero" o } \\
\text { "gender". } \\
\text {-Reconoce } \\
\text { necesidad de } \\
\text { equidad en } \\
\text { oportunidades } \\
\text { para ambos } \\
\text { géneros (hombres } \\
\text { y mujeres) } \\
\text {-Facilitar } \\
\text { condiciones } \\
\text { laborales para la } \\
\text { mujer }\end{array}$ \\
\hline Ambiental & $\begin{array}{l}\text { No se pronuncia. Al } \\
\text { contrario, la prioridad } \\
\text { es producir a toda } \\
\text { costa. }\end{array}$ & No se pronuncia & $\begin{array}{l}\text { Hay preocupación por } \\
\text { el tema ambiental, } \\
\text { hay evidencias de } \\
\text { crisis en algunos } \\
\text { sectores. }\end{array}$ & $\begin{array}{l}\text { Adquiere } \\
\text { relevancia el tema } \\
\text { ambiental y forma } \\
\text { parte de la ley y } \\
\text { agendas políticas, } \\
\text { económica y } \\
\text { sociales }\end{array}$ \\
\hline $\begin{array}{l}\text { Financiamiento } \\
\text { de Planes y } \\
\text { Proyectos }\end{array}$ & $\begin{array}{l}\text { Sector privado y } \\
\text { Estado }\end{array}$ & $\begin{array}{l}\text { principalmente el } \\
\text { Estado }\end{array}$ & $\begin{array}{l}\text { Principalmente el } \\
\text { sector pivado }\end{array}$ & $\begin{array}{l}\text { Sector Privado, } \\
\text { Sector Público, } \\
\text { comunidad }\end{array}$ \\
\hline $\begin{array}{l}\text { Responsables de } \\
\text { la } \\
\text { Administración y } \\
\text { Gestión }\end{array}$ & $\begin{array}{l}\text { actores estatales y } \\
\text { privados }\end{array}$ & actores estatales & actores privados & $\begin{array}{l}\text { "partnership" } \\
\text { coordinación y } \\
\text { convergencia de } \\
\text { intereses, actores } \\
\text { privados, públicos } \\
\text { y comunidad }\end{array}$ \\
\hline
\end{tabular}

Fuente: Referencias ( ). Elaboración LA Cardenas J. 1996 


\section{2.- El marco teórico del Desarrollo Sustentable}

El Desarrollo Sustentable o desarrollo sostenido según sea la traducción del vocablo, se perfila como concepto por primera vez en el Club de Roma en 1972 aludiendo al vínculo existente entre crecimiento económico global y escasez de recursos naturales, en el informe Limits to Growth. Y en el mismo año se publica el libro Only One Earth que continua con esa línea. No obstante, se acuña oficialmente el término "Sustainable Development" en 1987, en el informe Our Commom Future, realizado por la Comisión Mundial sobre Desarrollo y Medioambiente, conocido como la Comisión Brundtland. (Hardoy et al, 1992). La comisión define el término como:

"... satisfacer las necesidades de la presente generación sin comprometer la habilidad de futuras generaciones para satisfacer sus propias necesidades..."

Al respecto hay que mencionar que hoy en día existen más de 80 definiciones del concepto Desarrollo Sustentable dependiendo de los enfoques que asigna cada cual, pero en términos generales se puede afirmar que hay dos corrientes de pensamiento: una focalizada en los objetivos de desarrollo y otra focalizada en los controles requeridos para el impacto dañino que causan las actividades humanas sobre el medioambiente. En otras palabras, la discusión se centra en la sustentabilidad de tipo ecológico más que en las metas de un desarrollo social y económico de una sociedad.

De hecho en el encuentro mundial organizado por las Naciones Unidas en Río de Janeiro, 1992, conocido como Earth Summit, una de las críticas realizadas por los países del Hemisferio Sur y organizaciones no gubernamentales fue el marcado énfasis en aspectos ecológicos que garanticen la sustentabilidad del sistema natural más que en aspectos derivados del desarrollo social y económico, situación prioritaria para dichos países, pues la sustentabilidad ecológica per se no contribuye directamente a reducir los niveles de pobreza.

Al respecto, se puede afirmar que ha habido una evolución o madurez en él vínculo entre desarrollo y medioambiente, pues entre los setenta y ochenta la postura de fondo era limitar el crecimiento para no agotar los recursos naturales no renovables, sin embargo entre los ochenta y noventa, la postura es que exista crecimiento económico para combatir la pobreza, pero con restricciones ambientales. En otras palabras se sustituye la postura del "no crecimiento" por un "crecimiento verde", lo cual significa pasar de una dicotomía entre desarrollo y medioambiente a una concomitancia. Así se llega paulatinamente a concebir el concepto del Desarrollo Sustentable como una nueva forma de desarrollo para enfrentar el futuro de las naciones.

El concepto de sustentabilidad tiene su origen en la ecología toda vez que su definición está basada en los problemas ambientales derivados de la alteración de los ciclos de la naturaleza. La sustentabilidad ha sido definida de muchas maneras según el contexto, pero inicialmente ha sido definida como la capacidad de permanencia en el tiempo de 
un proceso que perdura gracias a la retroalimentación y en particular se refiere al uso de los recursos naturales, que pueden verse afectados por la degradación ambiental de tres tipos:

(i) el agotamiento de la calidad o cantidad del recurso usado en el consumo o la producción de actividades;

(ii) la contaminación o sobresaturación de la capacidad de la naturaleza de absorber y reciclar desechos llegando a un límite de quiebre, irreversibilidad del medioambiente;

(iii) reducción en la biodiversidad.

Ejemplo de (i) consumo ilimitado de ostras fuera de temporada, ejemplo de (ii), aire contaminado en Santiago, ejemplo de (iii), tala indiscriminada de parques nacionales en el Sur de Chile y consecuente extinción de fauna dependiente de esa flora.

Un tercer enfoque del concepto de desarrollo sustentable emanado de las agencias de ayuda bilateral, organizaciones internacionales, y agencias de las Naciones Unidas está relacionado con la continuidad del proyecto asistido económicamente por estas agencias, vale decir si el proyecto es capaz de continuar con los objetivos de desarrollo una vez terminado el apoyo externo de estas agencias. En este caso la sustentabilidad está más relacionada con el diseño operativo y la mantención o también conocido como la gestión institucional.

Como puede verse el desarrollo sustentable adquiere diversas connotaciones según el contexto, sin embargo son aproximaciones que van contribuyendo a la maduración del concepto e integración que se hace explícita a final de los noventa. Algunas aproximaciones conocidas mundialmente son las siguientes:

Mitlin en los '1992 expone dos vertientes principales, a saber: la dimensión ecológica y los objetivos de desarrollo social expresados en la figura $\mathrm{N}^{\circ} 1$

Componentes del desarrollo sutentable (Mitlin, 1992).

Minimizar el uso de recursos no renovables (combustible fósil, minerales, perdida de la biodiversidad)

\section{Desarrollo}

Uso Sustentable de recursos renovables (acuíferos, cortes de agua fresca, suelos, biomasa)

\section{Sustentable}

Mantención dentro de la capacidad de absorción de los vertederos de desechos locales y globales. (Gases del efecto invernadero, destrucción química del ozono de la estratosfera, químicos persistentes, etc.)

Acceso a adecuada sobreviviencia (a menudo implica acceso a los recursos naturales)

\section{Elección}

Satisfacer las necesidades básicas

Participación en políticas locales y nacionales junto con el respecto de los derechos 
humanos

Acceso a una adecuada vivienda y medioambiente sano (incluyendo los servicios básicos)

Fuente: Environment and Urbanization. Volume 4 № 2 October 1992

Otro autor que ha desarrollado un concepto que apoya la sustentabilidad desde la perspectiva ecológica es el canadiense Rees (Rees, 1992), quien argumenta que la capacidad de carga - "carrying capacity" - del capital natural debe revisarse a la luz de los cambios ecológicos globales. Afirma que las ciudades no son lugares geográficamente discretos sino que la tierra ocupada por los residentes necesita de recursos naturales y tierras que van mucho más allá de los límites administrativos o del área construida, en consecuencia la ciudad deja una huella ecológica - ecológica footprint - que va más allá de las fronteras del área urbanizada.

Surge entonces la noción de bioregión urbana, vale decir una región urbanizada que considere la dependencia que tiene sobre un territorio mayor que el que ocupa su área urbanizada y contemple así la capacidad de carga de esos sistemas globales naturales. Esto es notorio en las regiones del Norte y del Sur, pues los países más desarrollados tienden a tener una huella ecológica mucho mayor que los países menos desarrollados y es aquí donde se presenta un conflicto geopolítico entre ambos hemisferios.

En este sentido establece una relación estrecha entre ecología y economía urbana, afirmando que no solamente comparten la misma raíz semántica sino que también el mismo punto de interés. Pero con el nacimiento de la economía clásica, a comienzos del siglo XX, se abandonaron las raíces organizas clásicas, con lo cual se distancio enormemente de la ecología llegando a constituir dos puntos de vista antagónicos y competitivos, vale decir una suerte de dicotomía entre crecimiento económico y calidad ambiental.

Sin embargo, se hace necesario repensar el desarrollo urbano a fin de compatibilizar ambos aspectos pues es claro que tarde o temprano los recursos naturales no renovables serán agotados y los recursos renovables alcanzaran el límite de quiebre de la renovación. Esto a pesar de que las principales corrientes económicas actuales argumentan el siguiente mito: la capacidad de carga del ecosistema global es infinitamente expandible; pues la tecnología es capaz de mejorar la productividad, y el capital natural puede substituirse por un capital manufacturado y el comercio interregional puede aliviar cualquier restricción en el crecimiento local. (Hardoy, op cit)

En otro orden, figuran los objetivos de desarrollo como tema central para avanzar hacia el desarrollo urbano sustentable. En efecto, el economista ingles Harris argumenta que dadas las tendencias de urbanización de los países en desarrollo en la última mitad del presente siglo, la población urbana ha aumentado enormemente sin precedentes y que ha seguido el movimiento de las firmas industriales para su localización urbana.(Harris, 1992) Como consecuencia de este acelerado proceso de urbanización junto a políticas económicas y programas de inversión insuficientes, 
emerge la pobreza urbana junto a problemas sociales y el deterioro ambiental de las ciudades.

Entre las características más impactantes de este proceso de urbanización se pueden mencionar los asentamientos ilegales localizados en las ciudades; la existencia de viviendas sin servicios básicos tal como agua, alcantarillado, energía; el aumento de la morbilidad producto de la falta de infraestructura sanitaria, etc. y en las grandes ciudades, las congestiones gigantes de tráfico, la proliferación de la violencia y el crimen, la expansión urbana a costa de tierras agrícolas, etc.

Considerando las distintas aproximaciones hacia los objetivos del desarrollo, en los noventa se formula nuevas propuestas políticas conducentes a la búsqueda de un desarrollo integral que pretende poner esta vez el énfasis en los tres enfoques: el económico, el social y el ambiental.

Es así como el Banco Mundial en 1991 presenta el informe Política Urbana y Desarrollo Económico: una agenda para los noventa, haciendo énfasis en el rol productivo de las ciudades y los estilos de asistencia gubernamental como facilitadores más que proveedores. Luego el Programa de las Naciones Unidas para el Desarrollo PNUD, sigue esta iniciativa con el informe Ciudades, Gente y Pobreza: cooperación de Desarrollo Urbano para los 1990, enfatizando la dimensión humana o social del desarrollo más que la simple dimensión económica. Por su parte el Centro de las Naciones Unidas para los Asentamientos Humanos (Habitat) enfatizara que en el desarrollo de los asentamientos humanos deberá tenerse muy en cuenta la variable ambiental pues constituye el soporte fundamental en el cual se emplazan los asentamientos humanos. (Cárdenas, 1993)

En suma el otro énfasis del desarrollo sustentable se perfila ya no solo desde la perspectiva ecológica del proceso sino también la social y la económica, ambos aspectos fundamentales para aminorar la pobreza.

En base al marco teórico recién analizado, en la figura $\mathrm{N}^{\circ} 2$ se elabora un esquema conceptual holístico del Desarrollo Sustentable, en el cual aparecen los tres componentes básicos integrados en pro de un mismo objetivo.

Esquema conceptual del desarrollo sustentable

Incremento de productividad

(Crecimiento macroeconómico y economía urbana)

\section{Desarrollo Sustentable EQUIDAD SOCIAL PROTECCION MEDIOAMBIENTE}

(Pobreza y Género) (Natural y construido)

Elaboración: Cardenas, L.A. (1996) 
En breve, el desarrollo sustentable se fundamenta en la integración de tres componentes que interactúan entre sí en cada asentamiento humano. Es importante mencionar que alguna literatura utiliza con frecuencia el apellido de "urbano sustentable" debido a las tendencias mundiales hacia la urbanización, vale decir que en los próximos decenios las áreas rurales serán cada vez menos y de menor rango. No obstante lo anterior, el desarrollo sustentable como modelo puede ser aplicado en también en las áreas rurales, las cuales dependen fuertemente de los recursos naturales para su subsistencia. Por tanto se estima conveniente utilizar el término asentamiento humano más que la clásica y tal vez pasada de moda distinción entre urbano y rural.

En este mismo sentido surge el vocablo ciudad como relevante pues se ha demostrado que la escala adecuada para la acción es precisamente el nivel local, debido a que, a partir de las bases, se pueden revertir los procesos de deterioro a nivel regional y a nivel global. Además, existen hoy en ida otros problemas asociados directamente al ambiente construido y a las formas de ocupación del espacio que surgen a partir del funcionamiento en las ciudades, como por ejemplo: el tráfico vehicular; la contaminación atmosférica, acústica, edáfica; la violencia y delincuencia en los espacios públicos; el deterioro del paisaje urbano; la destrucción del patrimonio arquitectónico y tejido urbano, etc. (Girardet, 1990).

Todas estas materias pertenecen al estudio del medioambiente construido y adquiere una importancia relativa mayor que los problemas globales tal como el calentamiento de la tierra, la deforestación del Amazonas, o la sobreexplotación del recurso agua, etc. Pues estos últimos son efectos de problemas que tienen su causa en los sistemas de producción de las ciudades, en los patrones de consumo del habitante citadino, en las formas arquitectónicas y en la organización del espacio de la ciudad.

En breve, el significado de los componentes del desarrollo sustentable puede ser explicado de la siguiente manera: el incremento de la productividad, el cual está referido no solamente al crecimiento macroeconómico tradicionalmente medido en parámetros como el producto geográfico bruto o el ingreso per cápita, sino que se estudia en relación al potencial económico que tiene cada ciudad o asentamiento humano, vale decir los recursos humanos disponibles, y sus niveles de educación y salud, la capacidad de inversión, las infraestructuras disponibles y su vida útil, la arquitectura urbana de la ciudad, la organización espacial de las actividades, los recursos naturales disponibles, etc. En suma las potencialidades, fortalezas, debilidades y amenazas de su medio para vivir y laborar en un entorno seguro (ej. vivienda, agua, alcantarillado, medios de transporte, espacios abiertos de recreación, etc.) (Harris, op cit).

El segundo término, la equidad social, entendida en un sentido diferente a la igualdad social. La equidad está referida al grado de accesibilidad que tengan los individuos de una sociedad frente a las oportunidades que existen en la misma, por ejemplo, laboral, participación en el ingreso fiscal, facilidad de acceso a los servicios como salud, educación, previsión, etc., facilidad para movilización entre lugares, acceso a 
infraestructura, etc. El énfasis está focalizado en los segmentos de la población más desposeídos y o discriminados como son el sector pobre y el género femenino, entre muchos otros. (Levy, 1992) (Mosher, 1992)

El otro término, la protección ambiental, entendida en un sentido más amplio que lo ecológico. Pues en este componente se distinguen el medio natural y el medio construido. El primero dice relación con la ecología de los recursos naturales tales como el agua, el aire, el suelo, la producción agrícola, forestal, minera, etc. El segundo dice relación con la morfología de la ciudad entendida como la arquitectura urbana y el sistema de espacios públicos, el patrimonio arquitectónico, la estructura urbana, etc. (Hardoy, op cit) (CEC, 1990). Cabe mencionar que la protección ambiental es solamente un enunciado, pues incluye también otras concepciones tales como la conservación, la rehabilitación, el control de la explotación de los recursos, los planes de manejo, etc.

Como puede verse el desarrollo sustentable se fundamenta en un enfoque trial que propone la integración de tres dimensiones para avanzar hacia el camino del desarrollo de los asentamientos humanos en el próximo siglo.

\section{3.- Las nuevas agendas políticas para los 1990 y la Agenda Local 21}

La reacción política de los organismos internacionales de financiamiento, las agencias de ayuda y asistencia, frente al debate y DISCUSION de la propuesta conceptual del Desarrollo Sustentable no se hizo esperar y a final de los ochenta y principios de los noventa aparecen las llamadas agendas políticas para los 1990. Es así como en 1987, UNCHS (Hábitat) presenta el documento base denominado " Nueva agenda para los Asentamientos Humanos"; luego en 1990, UNDP presenta "Ciudades, gente y pobreza: cooperación de desarrollo urbano para los noventa"; y finalmente el Banco Mundial en 1991 presenta su documento "Política Urbana y Desarrollo Económico: una agenda para los noventa".

Si bien las tres agendas tienen aspectos en común, también es cierto que cada una de ellas presenta sutilmente énfasis diferentes, aunque no necesariamente incompatibles. Así es como la agenda del Banco Mundial presenta cuatro tópicos claves: la productividad urbana, la pobreza urbana, el medioambiente urbano sustentable y la investigación / desarrollo. Su visión está muy ligada a la perspectiva económica, por ejemplo las ciudades son vistas como máquinas de crecimiento económico. Por otra parte, la visión de UNDP enfatiza la dimensión social y económica, por ejemplo las ciudades son los lugares en los cuales mucha gente pobre vive sin acceso a ingreso, a oportunidades de empleo, salud, educación, etc.). Por último, la visión de UNCHS es similar pues concibe a la ciudad como los lugares fundamentales generadores de riqueza el cual provee el capital para todas las actividades humanas y así se constituye en la maquinaria para el mejoramiento social. (Cárdenas, 1993) 
Como resultado de estas propuestas, las naciones se reúnen para debatir y discutir sobre estos temas y así postular las agendas nacionales y acuerdos internacionales. Prueba de ello son los encuentros globales que se están realizando cada dos años en el mundo y son organizados por las Naciones Unidas. El primer encuentro de este tipo fue realizado en 1992, en Río de Janeiro denominado "Earth Summit"; luego en Manchester, 1994 el Global Forum denominado "Cities and Sustainable Development"; y en Istanbul, en 1996 el encuentro de Habitat II titulado "City Summit United Nation Conference on Human Settlement". En cada uno de ellos se pretende avanzar hacia formulaciones concretas en el marco del Desarrollo Sustentable y se ha manifestado una tendencia por acercar a los niveles locales a través de la formulación de marcos políticos desde el escenario municipal.

Como resultado del encuentro de Río en 1992, se formuló el documento conocido como Agenda Local 21 en la cual se establece como los países desarrollados y en desarrollo pueden trabajar hacia el desarrollo sustentable. Entre sus postulados esta la necesidad de compartir riquezas, oportunidades y responsabilidades entre el los países del Norte y Sur; entre diferentes grupos sociales dentro de cada país; con especial énfasis en las necesidades de la pobreza y los más desventajados en la sociedad; y pone se caracteriza por la focalizacion de la política en el nivel local.

La Agenda 21 representa el inicio de un proceso continuado para desarrollar políticas locales y construir sociedades ("partnership") entre las autoridades municipales y otros sectores para trabajar conjuntamente hacia el desarrollo sustentable. La Agenda distingue seis elementos claves en el proceso, entre los cuales los dos primeros están referidos a acciones al interior de la autoridad local mientras que los otros se relacionan con la comunidad más directamente. Estas acciones son las siguientes:

(i) Gestión y desarrollo de la práctica ambiental desde la propia autoridad local, (ii) integración de las metas del desarrollo sustentable a las propias políticas y actividades de la autoridad local, (iii) Toma de conciencia y educación a la comunidad, (iv) consulta e integración del público en general, ( $v$ ) mecanismos de Asociación, (vi) Medidas, monitoreo e informes de los progresos logrados hacia la sustentabilidad.

Entre los tópicos temáticos del desarrollo sustentable se mencionan aquellos definidos como de acción prioritaria, a saber:

mantenimiento

planificación de usos de suelo

políticas de transporte y programas

desarrollo económico

licitaciones

servicios a la vivienda

turismo y estrategias al visitante

estrategias de salud

bienestar, oportunidades equitativas y estrategias de pobreza

servicios ambientales 
Por su parte la OECD, Organización para la Cooperación Económica y el Desarrollo de los países desarrollados, también focaliza la acción ambiental en el "medioambiente urbano", entendido como la ciudad, y define tres temas prioritarios para las políticas ambientales en los noventa, a saber: la rehabilitación urbana, el transporte urbano y la energía urbana. (OECD, 1990).

Como puede verse, el factor común entre las diferentes respuestas políticas según sea el contexto del cual surgen es la focalización en la ciudad y la selección de un tema que normalmente involucra a muchas disciplinas para su estudio, vale decir la multidisciplinariedad. Esto conduce a una primera conclusión, y es que los estudios estarán centrados principalmente en las ciudades y los recursos humanos estarán orientados a la formación de equipos multidisciplinares para abordar el desarrollo sustentable.

\section{4.- Un paradigma de Gestión Urbana Sustentable}

Luego de establecer la Agenda Local 21, comienza a manifestarse globalmente una fuerte tendencia a promover la gestión como un medio de moverse desde la idea hacia la acción. Esto significa avanzar desde la propuesta política hacia la formulación de planes, programas y proyectos que materialicen los objetivos políticos. En este camino, figuran algunos proyectos de planificación y gestión urbana integrada que conllevan los principios del desarrollo sustentable y se constituyen así en unos buenos ejemplos para el aprendizaje, tal es el caso de la ciudad de Curitiba al Sur de Brasil.

El Plan de Urbanismo de la ciudad de Curitiba, se desarrolla en un periodo de 25 años entre 1965 al 1990, pasando por distintos periodos políticos, pero manteniendo un horizonte común, el desarrollo social, económico y urbano de Curitiba. El arquitecto Ravinovitch junto al alcalde Lerner actuaron coordinadamente desde la plataforma política y técnica en el proyecto de la ciudad emplazada en una área de $430 \mathrm{kms}$ y con una población de 1.600 .000 hbts en 1990 .

En los sesenta, Brasil alcanzaba el peak de su proceso de urbanización y mientras el resto de las ciudades medias brasileñas se planificaban para el uso del vehículo particular, Curitiba lo hacía a la inversa, proyectar un sistema de transporte público asociado a los usos de suelo y al diseño del espacio público. La estructura del poder local se centraba en el nivel municipal, por tanto se facilitaron las condiciones para tomar decisiones propuestas por el Ayuntamiento para dirigir el proceso de crecimiento y regulación de la ciudad. Dado la escala de la ciudad, se postulaba la necesidad de realizar inversiones modestas y de menor costo en materias de transporte que proyectos onerosos y de gran escala como realizar un Metro.

El principio rector en planificación fue orientar la expansión física a lo largo de ejes lineales teniendo líneas exclusivas para buses expresos al centro de la ciudad, y reducir la concentración del empleo en el centro tradicional de la ciudad. Así se liberaba el uso vehicular del área central, en el cual yacían numerosos edificios de gran 
valor arquitectónico y espacios urbanos de calidad, y se entregaba al uso peatonal. De este modo se preservaba el patrimonio cultural de la ciudad. En la figura $N$ ' se observa una síntesis de la evolución del sistema de transporte público en Curitiba.

El sistema de transporte público contemplaba no solamente la planificación de los usos de suelo y el diseño de los espacios urbanos sino también incorporo un largo y efectivo proceso de gestión para materializar el Plan. Es así como se negoció con los empresarios privados del transporte un sistema de salarios fijados en función del kilómetro recorrido y no del número de pasajeros, con lo cual se controla la calidad del servicio y el costo del boleto. Para ello el Ayuntamiento creó una compañía paraestatal (URBS) que licitar las rutas y su regulación.

Por otro lado, el Ayuntamiento adquirió los terrenos colindantes a las vías de la red de transporte en forma previa al inicio de su construcción para evitar la especulación de los terrenos y la construcción de viviendas sociales de alta densidad. Así se observa que la gestión no solamente esta post proyecto sino que también se requiere previo al proyecto, para evitar que las plusvalías de terrenos ganadas por la ejecución proyecto sean adjudicadas a unos pocos propietarios privados.

\section{Evolución del sistema de transporte público de Curitiba}

1974 Implementación de las dos primeras líneas expresas de buses a lo largo de ejes estructurales norte y sur.

1978 tres nuevas líneas de buses expresos agregadas a lo largo de los ejes estructurales.

1978 Introducción de un nuevo sistema computarizado de control de áreas de tráfico.

1979 Introducción de un boleto social; un boleto standard pagado por todos los usuarios de buses lo cual significó mayores beneficios para los usuarios de buses que vivían en la periferia de la ciudad (grupos pobres), así los viajes cortos subsidiaban a los viajes largos.

1979 Introducción de líneas de buses interdistritos para complementar el sistema de transporte público existente.

1982 Aperturas de nuevas conexiones entre el centro de la ciudad y la ciudad industrial. Mejoramiento de las rutas interdistritos.

1991 Introducción de un sistema de buses rápidos.

Junto al sistema de transporte público, se diseñaron mecanismo de regulación para evitar usos de suelo y edificios degradantes para el entorno urbano y ambiental, tales como los estacionamientos en el centro y se dispusieron en cambio plazas y jardines para el uso recreacional del habitante urbano.

Los beneficios del proyecto son de diversa índole, de tipo social, económico, ambiental, arquitectónico, urbanísticos, entre los cuales se mencionan la accesibilidad de todos los grupos socioeconómicos a cualquier parte de la ciudad; la eficiencia del servicio de transporte público tales como frecuencias de tiempo regulares, flota de buses nuevas 
(máximo 3 años de antigüedad), seguridad para el uso del peatón, control de la velocidad, etc.; buenas relaciones con el sector privado empresarial del transporte. Curitiba tiene el más bajo índice de contaminación atmosférica de Brasil, inexistencia de congestiones vehiculares en el centro de la ciudad; preservación del patrimonio arquitectónico del centro, creación de espacios públicos peatonales en el centro histórico de la ciudad; creación de nuevos parques y jardines. etc.

\section{5.- Conclusiones}

Para terminar se puede mencionar algunas conclusiones tales como que el caso de Curitiba contempla aspectos de desarrollo social, económico, y ambiental simultáneamente sobre un medio construido como es la ciudad, por esta razón se considera un buen ejemplo de desarrollo urbano sustentable, pues incluye todos los aspectos del desarrollo y balancea los costos y beneficios de cada uno de ellos.

Por otra parte, la planificación está fuertemente apoyada por el nivel político y una eficiente administración que trasciende la actitud pasiva de proveedor de servicios y adopta una actitud constructiva y ejecutiva para la realización del objetivo. Esta postura pasa necesariamente por la negociación entre el sector público, el sector privado y los intereses de la comunidad. Este modelo de negociación se conoce como el "partnership" o asociación entre las partes interesadas, característica también de la práctica del desarrollo sustentable.

Finalmente, otra conclusión está referida a la forma de abordar estos proyectos desde perspectivas multidisciplinares, pues dada la complejidad del Plan y Proyecto, se requiere de un equipo formado por profesionales y técnicos de diversas disciplinas, en la cual los directores tengan la visión global y no solamente sectorial que permita encausar adecuadamente el Plan de Urbanismo. Cabe mencionar lo importante que es en el Plan de Urbanismo, el diseño urbano y la visión espacial de la ciudad, pues cualquier medida repercute también sobre el medioambiente construido como universo de acción.

\section{Referencias}

CÁRDENAS, LA (1993) Validity of town planning instruments to achieve sustainability. The case of local development plans in Santiago de Chile. DPU, University of London, London.

HARDOY, J., Mitlin, D., et D., Satterthwaite (1992) Environmental Problems in Third World Cities. Earthscan Públications. London.

HARRIS, N. (1990). The End of the Third World. Newly industrializing countries and the decline of an ideology. Ed. Penguin, London.

HARRIS, N. (Ed.) (1992). Cities in the 1990s. The challenge for developing countries. UCL Press. London. 
HARRIS, N et I. Fabricius (Eds.) (1996). Cities \& Structural Adjustment. UCL Press. London.

GIRARDET, H. (1995) The Gaia Atlas of Cities. New directions for sustainable urban living. Gaia Books Límited. London.

HUNT, D., (1989). Economic Theories of Development. An analysis of competing paradigms. Harvester Whatsheaf.

LGMB (1994) Local Agenda 21 Principles and Process. LGMB. Luton.

OECD (1990) L'environnement urbain: quelles politiques pour les annees 1990 ?. OECD. Paris.

REES, W. (1992) "Ecological footprints and appropiated carrying capacity: what urban economies leaves out". Environment and Urbanization Vol $4 N^{`}$ 2, London.

RABINOVITCH, J. \& J. Leitman (1993) Environmental Innovation and Management in Curitiba, Brazil WORLD BANK-UMP. Washington DC.

UNCHS (1987) A new agenda for human settlement. Washington DC.

UNDP (1991) Cities, people, and poverty: urban development cooperation for the 1990's. Washington DC.

WORLD BANK (1991). Urban Policy and Economic Development; an agenda for the 1990's. Whashington DC.

WORLD BANK (1992). World Development Report 1992. Development and the Environment. Oxford University Press. Washington DC.

Nota: Publicado en Boletín del Instituto de la Vivienda INVI N033, Mayo 1998. Facultad Arquitectura y Urbanismo. Universidad de Chile. Santiago. 